\title{
ACESSIILIDADE INTEGRAL PARA UMA ESCOLA INCLUSIVA E DEMOCRÁTICA: ESTUDO DE CASO NA ESCOLA ESTADUAL PROFESSOR JOSÉ DA SILVEIRA CAMERINO
}

\author{
LIMA, Camila Costa de (1); \\ CARVALHO NETO, Aloisio Batista de (2) \\ LIMA, Suzann Flávia Cordeiro de (3) \\ (1) UFAL, Mestranda no Programa Dinâmicas do Espaço Habitado \\ e-mail:camila.lima@fau.ufal.br \\ (2) UFAL, Mestrando no Programa Dinâmicas do Espaço Habitado \\ e-mail:aloisio.neto@fau.ufal.br \\ (3) UFAL, Professora Associada da Universidade Federal de Alagoas \\ e-mail:suzann.cordeiro@fau.ufal.br
}

\begin{abstract}
RESUMO
Este artigo tem como objetivo descrever as condições arquitetônicas em relação a acessibilidade da Escola Estadual Professor José da Silveira Camerino do Centro Educacional de Pesquisa Aplicada CEPA em Maceió-AL, contribuindo para a discussão da inclusão social de todos no espaço escolar. Os métodos utilizados foram: observação, levantamento arquitetônico e entrevistas; buscando mapear os problemas encontrados, descrevê-los e por fim propor adequações. Os resultados alcançados neste artigo têm o intuito de fornecer subsídios para se repensar a acessibilidade do edifício, sendo observadas adequações para o acesso pleno de todas as pessoas.
\end{abstract}

Palavras chave: arquitetura escolar; acessibilidade integral; escola democrática.

\begin{abstract}
This article aims to describe the architectural conditions regarding accessibility of the State School Professor José da Silveira Camerino of the Center for Applied Research - CEPA in Maceió-AL, contributing to the discussion of the social inclusion of all in the school space. The methods used were: observation, architectural survey and interviews; trying to map the problems encountered, describe them and finally propose adjustments. The results achieved in this article are intended to provide subsidies for rethinking the accessibility of the building, observing adjustments for full access of all people.
\end{abstract}

Keywords: school architecture; integral accessibility; democratic school.

\section{INTRODUÇÃO}

Em nossas cidades vemos que a acessibilidade ainda é algo muito distante do ideal. Entretanto, observamos que nas escolas públicas o acesso é ainda mais deficitário. O projeto de inclusão mencionado na Constituição Federal de 1988 se estabelece a partir de ações do Poder Público com o intuito de assegurar a educação para todos em sua forma mais ampla, ou seja, o acesso e a permanência no ensino obrigatório, gratuito e de boa qualidade. 
Porém, lidamos com inúmeras barreiras que impedem que a Educação Inclusiva se torne realidade no cotidiano das nossas escolas. Uma destas barreiras é a falta de acessibilidade dentro do espaço escolar, que mesmo não solucionada no projeto inicial do edifício, deve ser adequada no ambiente construído para viabilizar o acesso de todos. Além disso, para alcançar tal inclusão social, uma das visões possíveis é estudar o ambiente construído a partir do conceito de acessibilidade de uma forma ampla e abrangente.

Tendo em vista a Lei de Diretrizes e Bases da Educação Nacional (Lei n. 9.394 de 20 de dezembro de 1996) que prevê a garantia de vagas na escola regular para educandos com deficiência desde a Educação Infantil, a instituição de ensino deve estar pronta para recebêlos. Isso compreende não só a adaptação do espaço arquitetônico da instituição como também a habilitação e capacitação de profissionais para que a inclusão das pessoas com deficiência, no contexto educacional, aconteça naturalmente.

De acordo com a ABNT NBR 9050/ 2015, acessibilidade é a "possibilidade e condição de alcance, percepção e entendimento para utilização, com segurança e autonomia, de espaços, mobiliários, equipamentos urbanos, edificações, transportes, informação e comunicação, inclusive seus sistemas e tecnologias, bem como outros serviços e instalações abertos ao público, de uso público ou privado de uso coletivo, tanto na zona urbana como na rural, por pessoa com deficiência ou mobilidade reduzida" (ASSOCIAÇÃO BRASILEIRA DE NORMAS TÉCNICAS, 2015, p. 2). Dessa forma, conforme disposto no art. 55 da Lei Brasileira de Inclusão da Pessoa com Deficiência (Lei n 13.146, de 6 de julho de 2015), "a concepção e implantação de projetos que tratem do meio físico [...] devem atender aos princípios do desenho universal, tendo como referência as normas de acessibilidade" (BRASIL, 2015, p. 14). Foi considerando isso, que o presente artigo tem como objetivo analisar as condições arquitetônicas em relação à acessibilidade da Escola Estadual Professor José da Silveira Camerino do Centro Educacional de Pesquisa Aplicada - CEPA em Maceió-AL, buscando contribuir para a discussão da inclusão social de todos no espaço escolar.

A escola em questão faz parte do grupo de escolas do Centro Educacional de Pesquisa Aplicada que servirá de estudo de caso na dissertação que está sendo construída por um dos autores desse trabalho. Entre as visitas realizadas in loco foram constatados alguns problemas referentes a acessibilidade devido, principalmente, a adaptações realizadas decorrentes de problemas em relação a alagamentos em períodos de chuva. $\mathrm{Na}$ busca em amenizar estes problemas foram negligenciados aspectos de acessibilidade do espaço escolar.

A escola deve se tornar um ambiente acessível e adaptado para inclusão de seus alunos. Muitas vezes, a solução para os problemas arquitetônicos e estruturais não está na construção de novos empreendimentos, mas nas adaptações necessárias desses espaços para que alunos e funcionários mantenham uma relação de autonomia e segurança no espaço escolar.

Para garantir espaços mais democráticos a escola, algumas atitudes devem ser tomadas para favorecer a acessibilidade como a instalação de rampas, corrimão, adequação dos pisos, revisão dos acessos, adequação dos sanitários e entorno do colégio. Entretanto, para que se alcance a acessibilidade de forma abrangente é preciso que os ambientes sejam adequados não só às necessidades funcionais, mas também às necessidades psicossociais de seus usuários. O termo, sob este prisma, pode colaborar na participação com segurança, conforto e autonomia nas diversas atividades da instituição, contribuindo para o resgate do sentimento de lugar, e, fora dos limites físicos, fornecer mecanismos para a inclusão social, através da atuação política (NEWEL; CAIRNS, 1993).

Os métodos utilizados para a análise do estudo de caso foram: observação, levantamento arquitetônico e entrevistas; buscando mapear os problemas encontrados, descrevê-los e por fim propor adequações. Os resultados alcançados neste artigo têm o intuito fornecer subsídios para se repensar a acessibilidade do edifício, sendo observadas adequações para o acesso pleno de todas as pessoas. 


\section{$\dddot{1}^{\text {eneac }}$}

Vale ressaltar que, a educação de qualidade é definida como aquela que é acessível e inclusiva, ou seja, que abre oportunidades para grupos historicamente excluídos e promove as reformas educacionais necessárias para que as escolas possam propiciar um ambiente adequado à aprendizagem e ao desenvolvimento humano.

A análise é ainda mais necessária se considerarmos que as condições do ambiente construído podem constituir fatores de risco ou de saúde. A criança e o adolescente passam grande parte do seu dia dentro da instituição escolar. Sabe-se que o contexto ambiental onde a criança e o adolescente crescem e se desenvolvem é crucial nas causas e manifestações dos problemas, especialmente nas questões de comportamento. De acordo com Okamoto (2002) este deve oferecer condições de acessibilidade para o usuário participar e interagir, desenvolvendo novas competências cognitivas e sociais. O ambiente construído com acessibilidade em seu sentido mais amplo pode constituir um elemento importante para estimular e favorecer o estabelecimento dos primeiros conceitos de cidadania e respeito às diferenças humanas, promovendo a inclusão social.

\section{PROCEDIMENTOS METODOLÓGICOS}

Para desenvolver estudos de acessibilidade de forma integral, é necessário ampliar o olhar e incluir outros elementos na avaliação do espaço que permitam examinar condições de apropriação e de verdadeiro acolhimento. Porém o presente artigo terá como foco principal o conceito de acessibilidade espacial, focando, principalmente, nas barreiras físicas.

A obtenção dos dados exigiu a combinação de três diferentes métodos de investigação: Observação, Levantamento Arquitetônico e Entrevistas, que resultaram na leitura espacial e serviram para coletar informações de fonte primária (crianças e adolescentes). Os diferentes instrumentos são descritos resumidamente nos parágrafos seguintes.

A observação foi não participante com a elaboração de relatório escrito de fatos e fenômenos referentes às atividades cotidianas realizadas e a acessibilidade integral - interações entre usuário-ambiente e usuário-usuário, que serviram de embasamento para as leituras das características de uso e apropriação. Para complementar, foram feitos registros de vídeos e fotos.

O levantamento arquitetônico foi realizado a partir de registros fotográficos e medição in loco. Elas orientaram na descrição dos seguintes itens: arranjo espacial e os atributos que permitiam acessibilidade ou ausência da mesma.

As entrevistas foram não estruturadas, seguindo Marconi e Lakatos (1996). A escolha do instrumento deu-se porque as perguntas abertas se moldavam às diferentes situações e respostas. Através destas entrevistas, os usuários puderam relatar suas impressões e expectativas quanto ao espaço. Tais relatos foram utilizados para confirmar os pontos positivos e negativos levantados pelos demais instrumentos.

Além dos métodos utilizados, o artigo apresenta parte da revisão de literatura das dissertações a serem defendidas futuramente pelos autores, apresentando os principais princípios da educação democrática e como isso se refletiu na materialização arquitetônica do presente estudo de caso, assim como uma revisão em relação ao tema acessibilidade. A arquitetura reflete transições tecnológicas e mudança de valores culturais, materializa uma ideia, um propósito ou uma ideologia, muitas vezes oculta. A materialização das ideias resulta em diferentes métodos de construção, ligados aos valores culturais da época, resultando em edifícios considerados como uma expressão dos conceitos e teorias de cada momento histórico. Assim, através da arquitetura também é possível especular sobre as características da sociedade que a produziu. 


\section{remes}

\section{EDUCAÇÃO DEMOCRÁTICA}

A discussão internacional sobre a democratização da educação inicia-se ainda no final do século XIX através de um conjunto de pedagogos que reivindicam uma educação centrada no aluno. O pedagogo americano John Dewey (1859-1952) revoluciona com sua pedagogia moderna e progressista que tem repercussão internacional, em especial na Europa (MONIZ, 2016). Em sua pedagogia Dewey critica a memorização, valoriza as atividades manuais e dá ênfase aos reais interesses dos alunos.

Outras correntes científicas e filosóficas que marcam o início do século XX irão influenciar as práticas pedagógicas contemporâneas, como a contribuição da psicologia e da sociologia que nortearam o desenvolvimento dos processos didáticos e conhecimento do indivíduo enquanto protagonista do aprendizado, as lições aprendidas com o pragmatismo de Dewey, a pedagogia montessoriana e a escola para o trabalho, as reflexões anarquistas, o socialismo de Althusser, o simbolismo de Bourdieu e a tendência construtivista de Piaget e Vygotsky que foram determinantes na reavaliação das intenções do sistema educacional nacional, a exemplo do que se produzia em outros países dos continentes americano e europeu (GARCIA,2016).

O ideário da Escola Nova, inspirado nas formulações de Dewey e defendido pelos educadores pioneiros no Brasil nos anos de 1930 preconiza uma escola voltada à formação integral do aluno, sintonizada às necessidades de uma sociedade em desenvolvimento. $O$ conceito de construção do conhecimento a partir da atividade dinâmica do aluno em interação com o meio surge como elemento central da teoria. No Brasil, foi Anísio S. Teixeira (1900-1971) o responsável pela introdução de conceitos de Dewey na educação. Trazendo a discussão da função social da escola e da integração da comunidade nas questões do ensino que futuramente vai inspirar a primeira Lei de Diretrizes e Bases da Educação Brasileira, LDB Lei 4.024/61 de 1961, concebida desde 1948.

Foi no final da década de 1940 que Anísio Teixeira teve a oportunidade de colocar em prática suas ideias educacionais inovadoras enquanto Secretário da Educação e Saúde da Bahia. Para isto, teve a ajuda de arquitetos que pudessem materializar suas novas propostas, como - caso de Diógenes Rebouças, responsável pelos projetos dos "Centros educacionais". Tratavam-se de complexos de educação em tempo integral que visavam alcançar as camadas populares, compostos pela escola-classe e pela escola-parque, também levando em conta a formação de professores (BUFFA e PINTO, 2002).

Vários Centros educacionais foram implantados em todo país. A cidade de Maceió, embora bastante distante da realidade de grandes centros formadores da arquitetura moderna no país como São Paulo, Rio de Janeiro e Recife, recebeu logo em 1958 um destes complexos educacionais inspirados no modelo de escola-parque idealizado por Anísio Teixeira cujo projeto pedagógico e arquitetônico causaram um grande impacto, com repercussão nacional.

Tal complexo se trata do antigo Centro Educacional do Estado (CEE), atual Centro Educacional de Pesquisa Aplicada (CEPA) (Figura 1), construído em Maceió durante a gestão do governador Arnon de Melo (1951-1956), a partir de recursos federais do Instituto Nacional de Estudos Pedagógicos (INEP), presidido na época por Anísio Teixeira.

Segundo Manhas (2011), o projeto do CEPA foi dos arquitetos baianos Diógenes Rebouças (autor de grande parte dos projetos educacionais idealizados por Anísio Teixeira) e José Bina Fonyat. Tal projeto apresentou um programa inovador para o cenário da época, constituindo um agrupamento de diversas escolas primárias e secundárias, equipamentos de lazer e esportes. 


\section{(x) $^{\text {reac }}$}

Figura 1 - Perspectiva do Centro Educacional de Pesquisa Aplicada (CEPA) com localização da Escola Estadual Professor José da Silveira Camerino

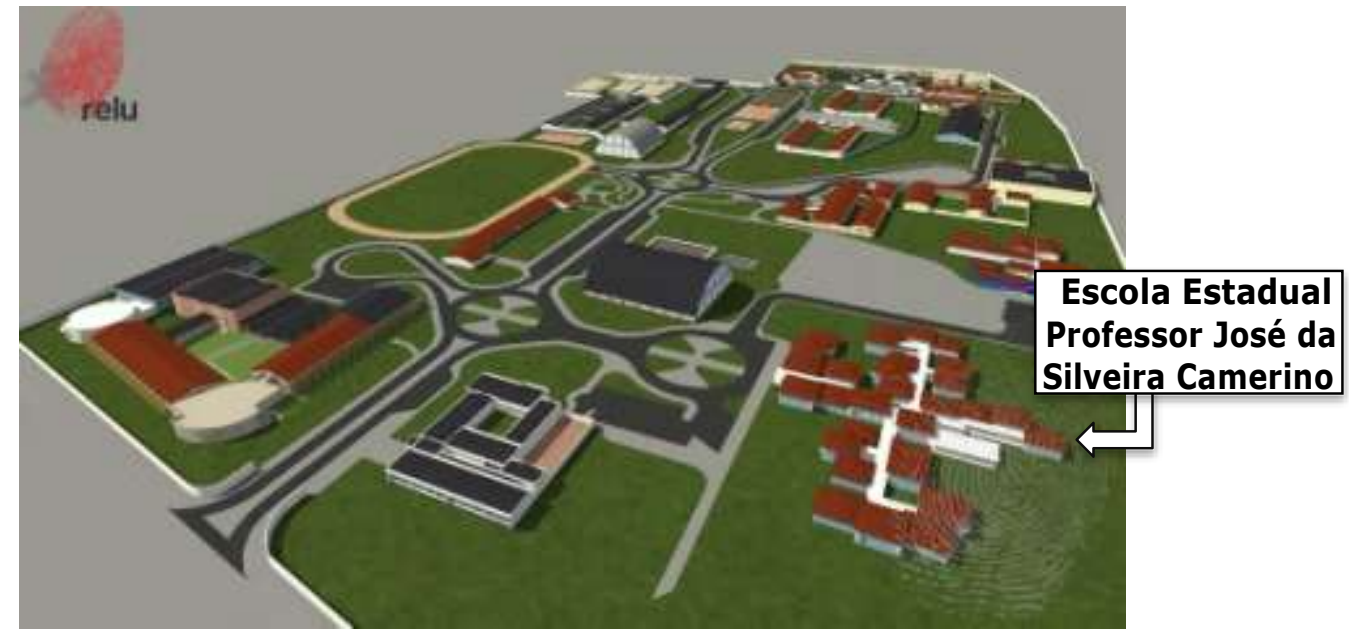

Fonte: Portal da Arquitetura Alagoana, acessado em 12 de jan. de 2018.

Esse amplo complexo foi inaugurado em 1958, mas começou a funcionar sem todas as etapas concluídas. Sua implantação se deu no ponto mais distante da Avenida Fernandes Lima do século XX, no bairro do Farol, configurando um novo eixo de expansão que teria modificado todo o território da cidade (LIMA JUNIOR, 2001), tornando-se o lugar de uma significativa produção da modernidade arquitetônica e urbanística local.

O CEPA constitui um exemplar expressivo desta utopia de escola democrática na qual se materializa arquitetonicamente através do modernismo, com sua linguagem plástica característica, rompendo completamente com a lógica que regia as primeiras escolas religiosas e grupos escolares da cidade.

Certos partidos arquitetônicos podem ser observados nos projetos construídos. Alguns se encontram repetidamente em diferentes escolas, constituindo tipologias organizacionais de planta, como a configuração em pátios, que permite uma melhor ventilação e aproveitamento da iluminação natural no interior dos prédios, funcionando ainda como ambientes para atividades coletivas, apresentações e brincadeiras, promovendo o desenvolvimento social das crianças e potencializando a função educativa da escola.

A volumetria dos edifícios que compõem o CEPA se expressa principalmente pelos jogos de volume entre os ambientes. Outra expressão plástica comum às escolas seria os cheios e vazios, das relações entre a alvenaria e as aberturas (CHING, 1998). Este tipo de organização permite uma grande flexibilidade na composição. Cada escola difere no formato, no tamanho, orientação e estrutura. Pode-se constituir uma volumetria dinâmica e aglomerar os ambientes prevendo-se sua expansão, sem descaracterizar a expressão original do projeto.

No caso específico da Escola Estadual Professor José da Silveira Camerino, o edifício possui grande presença destes cheios e vazios. Ele foi organizado em blocos de salas agrupadas com telhado aparente de quatro águas independente para cada sala. Estes blocos foram espalhados no terreno e conectados por uma circulação independente da estrutura de cada bloco. Esta circulação é marcada coberta por uma laje impermeabilizada que formam dois corredores principais, um que é a entrada do edifício e dá acesso aos blocos onde ficam a administração e coordenação da escola e outro corredor perpendicular ao primeiro que dá acesso as salas de aula, biblioteca e banheiros da escola. 
Figura 2 - Modelo tridimensional da Escola Estadual Professor José da Silveira Camerino

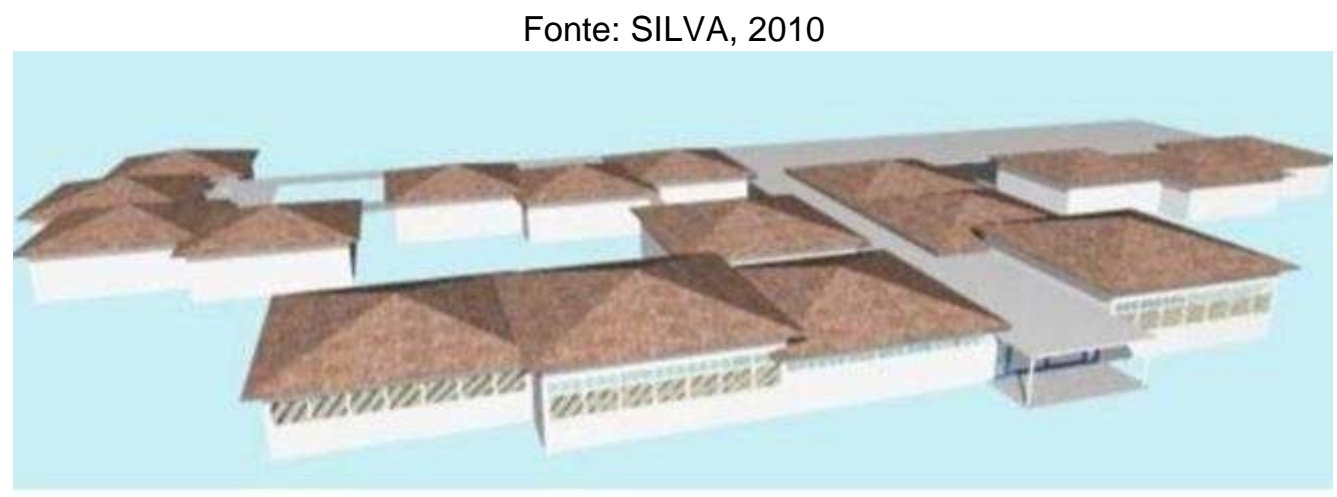

Os prédios do CEPA foram dispostos sempre de modo a melhor aproveitar o espaço do terreno e tiveram nitidamente a intenção de mudar a imagem da arquitetura escolar que se tinha até então, se utilizado das ideias educacionais voltadas para a formação integral dos alunos e de uma maior inclusão social dos mesmos. Porém, será que esse discurso democrático reflete um espaço igualmente equitativo? Considerando a acessibilidade como um dos fatores que propiciam a configuração de um espaço escolar democrático iremos nos deter na descrição de uma das escolas do CEPA, a Escola Estadual Professor José da Silveira Camerino, para iniciarmos esta discussão.

\section{ACESSIBILIDADE INTEGRAL}

O Centro Educacional de Pesquisa Aplicada (CEPA), por ser um complexo de educação em tempo integral que dispõe de espaços de lazer e esportes, destinado a camadas populares, se torna um espaço em que essas crianças e jovens passam a maior parte do seu dia. Para que se obtenha a inclusão proposta pela Lei de Diretrizes e Bases da Educação Nacional (Lei $n^{\circ} 9.394$ de 20 de dezembro de 1996), com garantia de permanência adequada às pessoas com deficiência desde a Educação Infantil, deve ser feita uma avaliação do ambiente construído tendo em vista a acessibilidade dos espaços.

As barreiras atitudinais, ou seja, atitudes ou comportamentos que impedem ou prejudicam a participação social da pessoa com deficiência de forma igualitária (BRASIL, 2015), são de resolução complexa e ligadas ao aumento de conscientização da população, no entanto, as barreiras arquitetônicas (ou urbanísticas) ou de comunicação também dificultam o acesso e uso do ambiente construído por pessoas com deficiência. Um ambiente sem barreiras deve ser pensado desde a sua concepção, porém, em espaços já construídos, podem ser previstas adaptações a fim de não restringir a participação dos educandos com deficiência e atingir o objetivo de inclusão almejado nas leis e normas técnicas sobre o tema.

Nesse contexto, o desenho universal, terminologia criada na década de 1980 por Ronald L. Mace, traz uma visão de concepção de projeto de arquitetura, urbanismo ou mesmo objetos que se adequam a ampla gama de usuários existentes através de sete princípios: uso equitativo; uso flexível; uso simples e intuitivo; informação perceptível; tolerância ao erro; baixo esforço físico e tamanho e espaço para acesso e uso. O desenho universal é considerado, dentre as leis que tratam sobre o tema, como por exemplo o Decreto $n^{\circ} 5.296$, de 2 de dezembro de 2004 e a Lei $n^{\circ}$ 13.146, de 6 de julho de 2015, item principal de atendimento dos projetos de arquitetura e urbanismo para a criação de espaços acessíveis e tendo como referências as normas técnicas de acessibilidade. A seguir, os sete princípios do desenho universal utilizados na avaliação são descritos brevemente.

- Uso equitativo: quando o projeto é útil e negociável às pessoas com diferentes habilidades. Na escola, isso pode ser avaliado na igualdade de acesso as salas de aula ou 
aos ambientes de lazer.

- Uso flexível: quando o projeto acomoda uma ampla gama de preferências e habilidades individuais. Numa escola, pode ser identificado na disposição dos mobiliários na sala de aula ou mesmo na diversidade de dimensões do mobiliário.

- Uso simples e intuitivo: quando o projeto é fácil de entender, independentemente de experiências anteriores, conhecimento ou habilidades linguísticas dos usuários. Na escola, podem ser observadas as rotas acessíveis ou o agenciamento dos espaços externos, bem como o mobiliário escolhido.

- Informação perceptível: quando o projeto comunica eficazmente a informação necessária ao usuário. No presente estudo, podem ser observadas se a comunicação é eficaz, seja através de placas, letreiros ou utilização de braile, guias de balizamento ou pisos táteis quando necessários.

- $\quad$ Tolerância ao erro: o projeto minimiza perigos e consequências adversas de ações acidentais ou não intencionais. Numa escola, podem ser avaliados o uso de elementos de proteção como corrimãos.

- $\quad$ Baixo esforço físico: o projeto pode ser usado de forma eficiente e confortável, com um mínimo de fadiga. No presente caso estudado, podem ser identificados as inclinações determinadas em normas ou mesmo o piso escolhido.

- Tamanho e espaço para o acesso e uso: é apropriado para o alcance e manipulação com uso independentemente do tamanho do corpo, postura ou mobilidade do usuário. $\mathrm{Na}$ escola, podem ser analisados os espaços dispostos para a aproximação do mobiliário, como cadeiras e bebedouros.

Quando se aborda a acessibilidade espacial, considera-se que a pessoa consiga utilizar, com segurança e autonomia, total ou assistida, dos espaços e mobiliários para que se desloque de maneira independente e confortável, assim conseguindo participar das atividades que estão sendo desenvolvidas. A ABNT NBR 9050/2015 traz em seu item 10.15 um tópico específico para escolas com exigências de rotas acessíveis, sanitários acessíveis, mobiliário interno acessível com áreas de aproximação e manobra.

Alcançar a acessibilidade em um espaço escolar é passar a compreendê-lo como um ambiente que possibilite, verdadeiramente, a vivência, a inclusão social e o desenvolvimento humano através da participação ativa de todos em cada ambiente e não como um espaçotempo de aprendizagem restrito a uma sala de aula. Ressalta-se ainda que para uma acessibilidade integral, segundo a definição de Savi e Dischinger (2016), é necessária a eliminação das barreiras até que as pessoas mantenham um sentimento de pertencimento ao lugar. Para isso, se utilizam de quatro componentes básicos: orientabilidade, deslocamento, comunicação e uso. Sendo a orientabilidade a capacidade de saber onde estar e para onde ir, de maneira autônoma; o deslocamento as condições ideais de movimento em percursos horizontais ou verticais; a comunicação as condições de troca de informações interpessoais e o uso dado pela possibilidade de participação do indivíduo em atividades desejadas, sem necessidade de conhecimento prévio.

\section{RESULTADOS: SUGESTÕES ERECOMENDAÇÕES}

O terreno onde se localiza o Centro Educacional de Pesquisa Aplicada (CEPA), de acordo com o mapa base de Maceió, possui curvas de nível que chegam a 45m de altitude, enquanto seu entorno possui, em média $50 \mathrm{~m}$. Devido a esse fator geográfico e a dificuldade no planejamento da drenagem urbana da cidade, com falta de áreas verdes que possam escoar essa água da chuva, o entorno acaba direcionando uma grande quantidade de água para esse terreno. Com isso, muitas das soluções adotadas no CEPA são para evitar que a água invada as escolas, criando barreiras arquitetônicas para a acessibilidade.

A Escola Estadual Professor José da Silveira Camerino, estudo de caso deste artigo que faz parte do grupo de escolas do Centro Educacional de Pesquisa Aplicada que servirá de estudo 


\section{(x) $^{\text {reac }}$}

de caso na dissertação de um dos autores, passou por algumas adaptações realizadas decorrentes de problemas em relação a alagamentos em períodos de chuva. $\mathrm{Na}$ busca em amenizar estes problemas foram negligenciados aspectos de acessibilidade do espaço escolar.

As entradas das salas de aula, por exemplo, possuem desnível acentuados para evitar a entrada de águas pluviais, formando um degrau para o acesso das pessoas. Em algumas salas também é possível constatar a presença de uma espécie de canaleta que separam o corredor do acesso das salas para passagem das águas pluviais nos momentos de chuva, devido ao fato da estrutura do corredor ser independente dos blocos de salas e deixar passar as aguas pluviais, que caem em sua laje impermeabilizada, para essa canaleta coletora (Figura 3). Esse tipo de solução retira a autonomia de acesso a estudantes usuários de cadeira de rodas ou mesmo que possuam algum tipo de mobilidade reduzida. Apenas a biblioteca possui uma rampa para vencer o desnível, porém aparentemente acima da inclinação máxima em norma (8,33\%). Logo, essa barreira impossibilita o cumprimento dos princípios de uso equitativo e baixo esforço físico componentes do desenho universal e compromete o deslocamento igualitário de todos, não permitindo apropriação desse local pelos diferentes usuários.

Figura 3 - Detalhe do encontro da laje do corredor com um bloco de sala, desnível entre o corredor e sala de aula, acesso entre o corredor e a biblioteca com rampa, respectivamente.
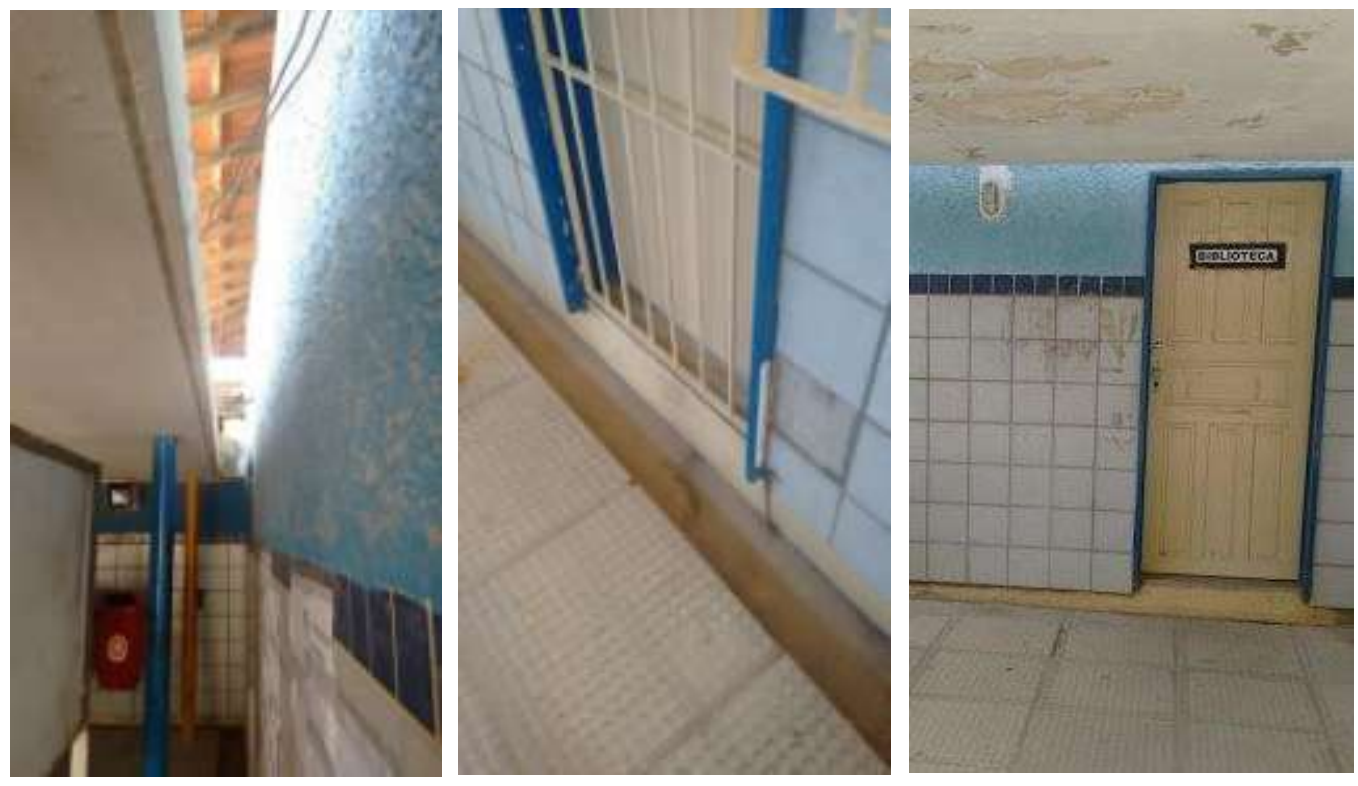

Fonte: Arquivo pessoal, 2018

O piso utilizado nos corredores possui superfície irregular e áspera, o que dificulta o deslocamento de pessoas com mobilidade reduzida, usuários de cadeira de rodas ou mesmo pessoas cegas. Com isso, dificulta o baixo esforço físico e também compromete o deslocamento de todos os usuários.

Ainda por conta das inundações, foram construídos patamares que deixam elementos como bebedouro e geladeira suspensos (Figura 4). O item 10.15.8 da ABNT NBR 9050/2015 exige que nas escolas, todos os elementos do mobiliário da edifcação, como bebedouros, guichês e balcões de atendimento, bancos de alvenaria, entre outros, devem ser acessíveis. Essa disposição de elementos na escola em estudo, além de não atender a norma técnica de acessibilidade, não cumpre os princípios de uso equitativo do espaço para acesso e uso; há também uma barreira de uso para a acessibilidade integral. 


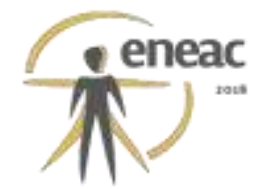

Figura 4 - Adequações feitas com degraus nos equipamentos da escola como o bebedouro no pátio coberto e a geladeira na cozinha do refeitório.

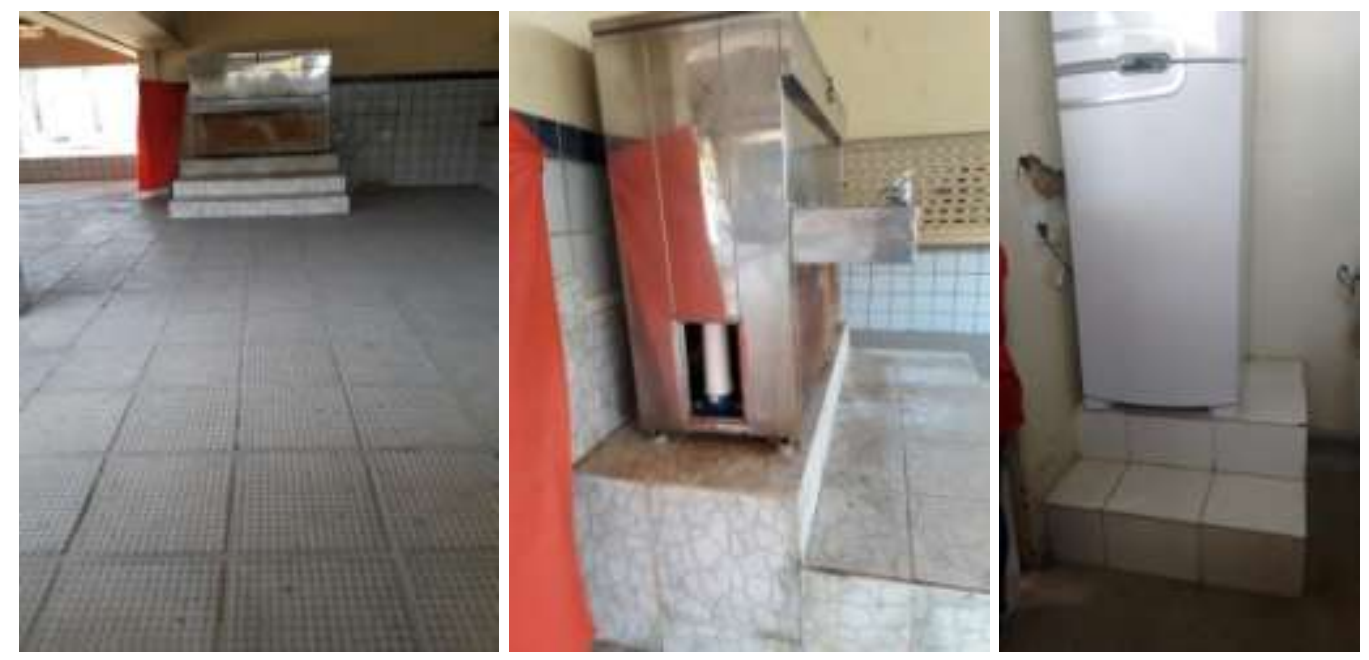

Fonte: Arquivo pessoal, 2018

Figura 5 - Espaços externos
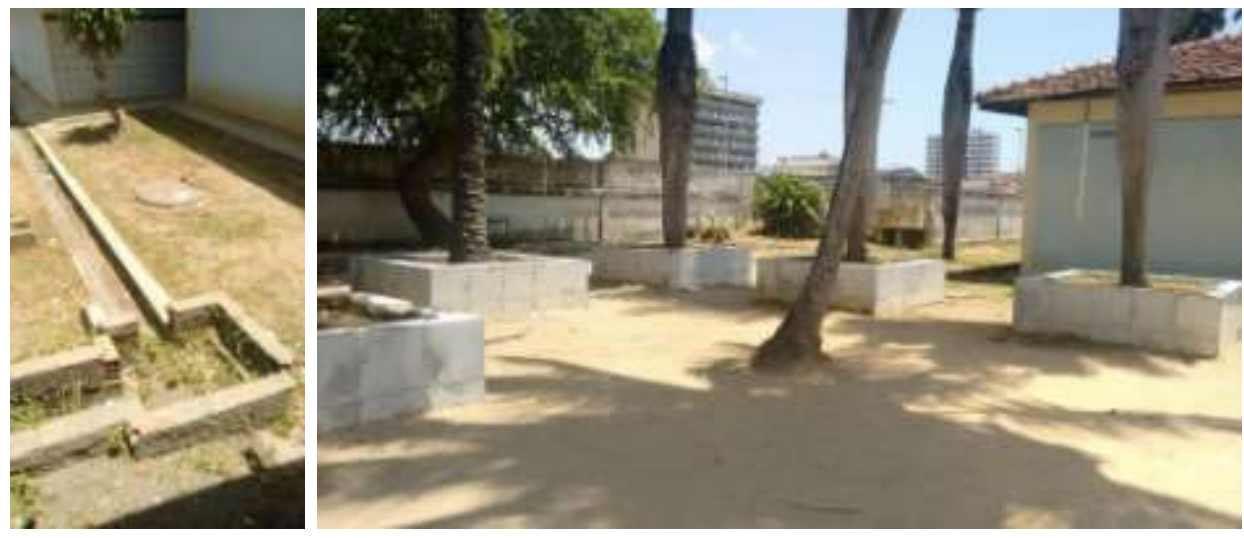

Fonte: Arquivo pessoal, 2018

O agenciamento dos espaços externos ao bloco de salas de aula não proporcionam definições claras de caminhos que se devem seguir, além de não possuírem rotas acessíveis aos demais espaços. Dessa forma, cria-se uma barreira arquitetônica que impossibilita a existência dos princípios de uso simples e intuitivo e informação perceptível. Há também barreiras na orientabilidade, pois o usuário pode não se localizar de maneira autônoma e de uso, já que o espaço é impossibilitado de ser utilizado por todos para as atividades, dificultando sua apropriação pelos usuários.

\section{CONSIDERAÇÕES FINAIS}

Uma escola inserida num centro de educação, como o estudado nesse trabalho, onde crianças e jovens passam uma grande parte do seu dia, deveria propiciar espaços acessíveis aos seus diversos usuários, ainda mais se levado em consideração o discurso legal sobre a inclusão das pessoas com deficiência e mobilidade reduzida. Com uma maior gama de pessoas e diversidade de experiências, esses espaços poderiam cumprir melhor seu papel de desenvolvimento do ser humano e crescimento pessoal. 


\section{(x) $^{\text {reac }}$}

O planejamento urbano da cidade, no entanto, tem papel determinante nessa perda de acessibilidade da escola. A elaboração de barreiras para as águas das chuvas acabam se transformando em barreiras físicas para as pessoas e para a apropriação do espaço por completo, para uma acessibilidade integral. Algumas escolhas de materiais ou mesmo o descuido no momento da concepção dos espaços, como por exemplo a falta de agenciamento adequado dos espaços, acabam produzindo novas barreiras.

O discurso democrático das escolas que se baseia na autonomia do aluno e inclusão social encontra dificuldade de reprodução na prática devido as diversas problemáticas que devem ser solucionadas, desde a concepção do projeto, a escolha dos materiais, os aspectos do planejamento urbano ou mesmo a falta de recursos financeiros para adaptações dos espaços.

Apesar de propiciar educação a uma quantidade importante de crianças e adolescentes da cidade, espaços acessíveis e a apropriação desses pelos usuários, apesar de não ser fator único e determinante, pode reforçar a construção de uma sociedade mais consciente sobre a importância da inclusão social.

\section{REFERÊNCIAS BIBLIOGRÁFICAS}

ASSOCIAÇÃO BRASILEIRA DE NORMAS TÉCNICAS. NBR 9050: acessibilidade a edificações, mobiliário, espaços e equipamentos urbanos. Rio de Janeiro, 2015.

BRASIL. Decreto $\mathbf{n}^{\circ}$ 5.296, de 02 de dezembro de 2004. Disponível em: <http://www.planalto.gov.br/ccivil_03/_ato2004-2006/2004/decreto/d5296.htm>. Acesso em: 02 fev. 2018.

Lei Brasileira de Inclusão da Pessoa com Deficiência (Estatuto da Pessoa com Deficiência). Lei $n^{\circ} 13.146$, de 6 de julho de 2015. Disponível em:

<http://www.planalto.gov.br/ccivil_03/_ato2015-2018/2015/lei//13146.htm>. Acesso em: 02 fev. 2018.

BUFFA, Ester e PINTO, Gelson de Almeida. Arquitetura e educação: organização do espaço e propostas pedagógicas dos grupos escolares paulistas, 1893/1971. São Carlos: EDUFSCar, 2002.

CHING, Francis D. K.. Arquitetura, forma, espaço e ordem. São Paulo: Martins Fontes, 1998.

LIMA JÚNIOR, Félix. Maceió de outrora. Maceió: EDUFAL, 2001. 
MANHAS, A. C. B. S. et al. Conhecer para preservar: a documentação de complexos escolares em Maceió (AL) em um portal de arquitetura de interesse histórico, técnico e artístico. In: 9o SEMINÁRIO DOCOMOMO BRASIL, 2011, Brasília. Anais do 9o Seminário Docomomo Brasil, 2011.

SAVI, Aline Eyng; DISCHINGER, Marta; "ACESSIBILIDADE INTEGRAL COMO FERRAMENTA DE INCLUSÃO SOCIAL: Estudo de caso em casas de acolhimento para crianças e adolescentes em situação de vulnerabilidade social", p. 53-64 . In: Anais do VI Encontro Nacional de Ergonomia do Ambiente Construído \& VII Seminário Brasileiro de Acessibilidade Integral [Blucher Design Proceedings, v.2 n.7]. São Paulo: Blucher, 2016. 